\title{
Complex neonatal airway surgery. Case report
}

\section{Cirugía compleja de la vía aérea en neonato. Reporte de un caso}

\author{
Daniel Martínez Catalá (D), Francisco Javier Escribá Alepuz (D), Pilar Argente Navarro \\ Department of Anesthesia and Resuscitation, Hospital Universitari i Politècnic La Fe. Valencia, Spain.
}

Correspondence: Calle Colón 49, Villena, España.

E-mail: cavalero91@hotmail.com

What do we know about this problem?

Neonatal airway pathology poses a challenge both for surgery as well as for anesthesia, with important variability in the published scientific literature as well as a paucity of protocols and guidelines for management and decision-making.

What new contribution is derived from this study?

This case report prompts a reflection about potential surgical approaches, with or without by-pass circulation, monitoring and anesthetic management, as well as potential complications that may arise in newborn patients. The importance of treating these cases in referral centers with multidisciplinary teams and consensus protocols is a key determinant of the probability of success in this complex condition.

How to cite this article:

Martínez Catalá D, Escribá Alepuz F], Argente Navarro P. Complex neonatal airway surgery. Case report. Colombian Journal of Anesthesiology. 2021;49:e941.

\section{Abstract}

Airway-related pathology poses a significant challenge to the pediatric anesthesiologist. This case report involves a 28 -day-old neonate diagnosed with congenital tracheal stenosis who underwent a slide tracheoplasty intervention with extracorporeal circulation. The anesthetic management is described, together with our experience in the face of a challenging situation, including adverse events during surgery.

\section{Key words}

Airway; newborn; congenital abnormalities; traqueal surgery; extracorporeal circulation.

\section{Resumen}

La patología relacionada con la vía aérea es uno de los grandes retos a los que se enfrenta un anestesiólogo pediátrico. En este reporte de caso se presenta una cirugía realizada en nuestro hospital. Un neonato de 28 días de vida, diagnosticado con estenosis traqueal congénita fue intervenido con traqueoplastia por deslizamiento, bajo soporte con circulación extracorpórea. Se documenta el manejo anestésico, y la experiencia de enfrentar un reto complejo, incluyendo los eventos adversos que ocurrieron durante la cirugía.

\section{Palabras clave}

Tráquea; recién nacido; anomalías congénitas; cirugía torácica; circulación extracorpórea. 


\section{INTRODUCTION}

Airway pathology in neonates is one of the biggest challenges for the pediatric anesthetist. Creating multidisciplinary teams and inter-hospital referral committees is crucial in order to study each individual case and arrive at joint decision-making.

The case of a 28-day-old neonate with a diagnosis of severe tracheal stenosis is presented. The patient had been intervened previously to correct an esophageal atresia type IV, with two failed extubations and a torpid course which finally unmasked the diagnosis of tracheal stenosis. A slide tracheoplasty with extracorporeal circulation support was proposed. A series of complications occurred during the intervention, as described in the discussion section below.

\section{CASE PRESENTATION}

This case involves a 28-day-old neonate taken to slide tracheoplasty with by-pass circulation support at Hospital de la Fe in Valencia (Spain).

Previously, at a different center, the patient had been diagnosed with esophageal atresia type IV and distal tracheo-esophageal fistula that required urgent surgery at 4 days of age. The postoperative course was torpid, with two failed extubations, which led to the diagnosis of severe mid-tracheal stenosis identified on fiberoptic bronchoscopy. Additional angiotomography studies (angio-CT) demonstrated a vascular ring component from the brachiocephalic trunk (Figure 1). When the diagnosis was made, the patient - intubated and under sedoanalgesia - was transferred to the referral Hospital specializing in these types of conditions, and scheduled for surgery.

After a few hours in the neonatal critical care unit, the patient was transferred to the operating room already intubated and under sedoanalgesia with fentanyl. Balanced anesthesia was initiated with sevoflurane, remifentanil and continuous rocuronium

FICURE 1. The 3D reconstruction of the angio-CT image shows the tracheal stenosis in relation to the esophagus and the arterial component, as well as the vascular ring arising from the right brachiocephalic trunk.

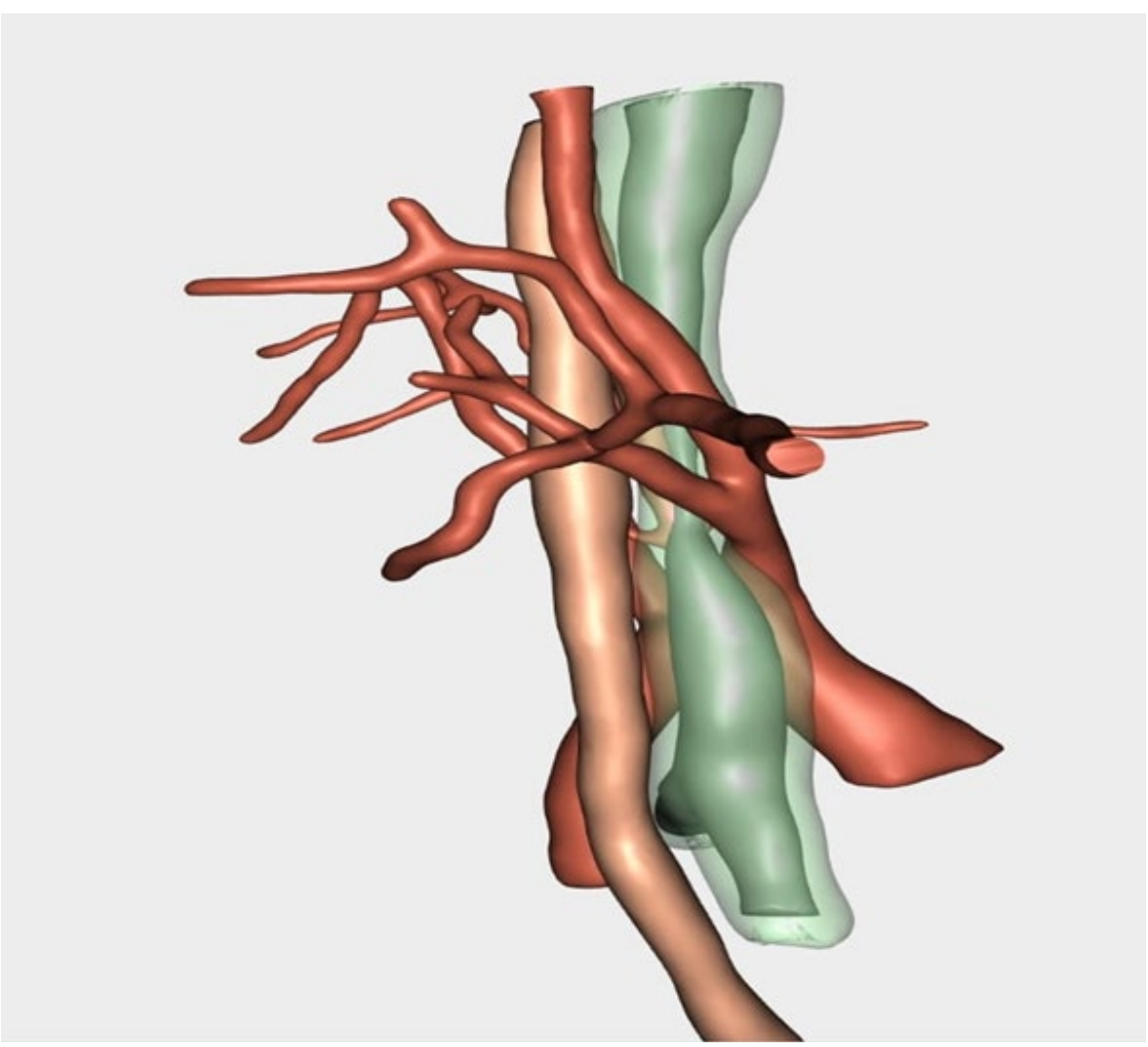

SOURCE: Authors.

perfusion. Monitoring was established using the arterial pressure curve analytical recording technology based on the PRAM method (pressure recording analytical method) and regional cerebral oxygen saturation using NIRS (near infrared reflectance spectroscopy) as well as various metabolic modules for $\mathrm{O}_{2}$ and $\mathrm{CO} 2$, consumption and oxygen index (OI) for perioperative management, with goaldirected therapy.

During surgery, balanced inhaled anesthesia was maintained with sevoflurane at a minimum alveolar concentration (MAC) of $1.3 \%$ and remifentanil at $0.3 \mu \mathrm{g} / \mathrm{kg} / \mathrm{min}$, and train of four-adjusted (TOF) continuous rocuronium perfusion. Ol values were maintained above $300 \mathrm{~mL} / \mathrm{min} / \mathrm{m} 2$, lactate remained normal with no variation over $20 \%$ of NIRS baseline values (INVOS ${ }^{\circledR}$ ) throughout the surgery. Weaning from by-pass circulation proceeded uneventfully, with milrinone support. Importantly, an intraoperative ventilatory event occurred during recovery from anesthesia. After changing head position from hyperextension to neutral, total absence of ventilation and capnography loss were detected, with peak pressure elevation, suggesting tube dislodgement. Direct laryngoscopy and tube removal were performed although tube placement appeared to be correct under direct vision. With new intubation, the tube was found to be occluded by a remaining blood clot from the surgical dissection. Careful aspiration with a suction probe was carried out and damage control fiberoptic bronchoscopy allowed to determine that the suture was intact. Surgical time was 6 hours. 
The patient was transferred to the neonatal critical care unit, intubated and under sedoanalgesia. On the second day of stay, the patient developed pneumonia, with positive bronchial aspiration culture for acinetobacter. The patient was extubated four days later and discharged after one week, with normal bronchoscopy findings and no complications.

\section{DISCUSSION}

In $40 \%$ of patients, the diagnosis of esophageal stenosis and tracheoesophageal fistula (1) is associated with tracheobronchial abnormalities. The presence of stridor or failed extubation may indicate association with bronchial stenosis. Some of these cases are often associated with vascular rings (2).

The airway stenosis protocol published by the task force of Hospital Universitario Politécnico de la Fe, in Valencia (Spain), was used to review the case. It is worth highlighting the importance of creating multidisciplinary teams specializing in pediatric airway pathology (3) in Level III hospitals that see these types of patients, because of their complexity. The slide tracheoplasty technique was selected because of stenosis greater than $50 \%$ of the tracheal thickness (4). It is the preferred intervention because it allows early extubation and results in less granulation tissue (5).

The recommended support system in these patients is peripheral veno-venous extracorporeal membrane oxygenation (ECMO) because of the need for oxygenation during the repair maneuver. However, the surgical team preferred extracorporeal circulation with central cannulation because of familiarity with the technique and the difficulty of using peripheral cervical vessels without a secure airway (6). Other options such as intubation distal to the stenosis in the bronchus or close to the carina, or jet ventilation, were discarded due to the size of the stenosis (Figure 2). Other tracheal reconstruction procedures may be supported with tracheostomy distal to the stricture, but that option was not possible in this case because of the mid distal location of the stenosis.

During recovery from anesthesia, the patient experienced an adverse event that could have been fatal. Tracheal suction at the time of weaning from by-pass circulation and ventilation verification is advisable in every surgery. In this case, in order to preserve the integrity of the surgery, careful suction under direct vision through fiberoptic bronchoscopy was required. However, the fiberoptic bronchoscope available at the hospital for these technical specifications does not have a working channel (Machida ${ }^{\circledR}$ ). For small sizes, only bronchoscopes with no working channel are available, making it impossible to aspirate secretions under direct vision. The risk of suctioning without direct vision was high because of potential injury of sutured structures: however, there was no other option to solve the problem. Fiberoptic bronchoscopy was used to check for damage, and suture integrity was confirmed.

It is crucial to follow protocols in cases as complex as this. The results of the surveillance cultures made in the unit where the patient was hospitalized before the surgery were overlooked during preanesthesia stage. As determined during the immediate postoperative period, and for epidemiological reasons, the patient was infected with acinetobacter from the critical care unit in which the neonate remained prior to the intervention. Surveillance cultures made in the original hospital did not show any infectious agent, although the study was incomplete.

In conclusion, a complex airway pathology in a pediatric patient requires a multidisciplinary approach through the creation of inter-hospital referral units. Adherence to the protocol along every step of the process is mandatory. Likewise, readers are offered a series of recommendations derived from teamwork experience and meticulous familiarity with the technical devices so that they can be adapted to the surgical requirements:

- Need for multi-disciplinary teams with expertise in complex pediatric airway pathology.

Reliance on assistance devices for patient oxygenation when needed during complex airway repair procedures.

- Suction under fiberoptic bronchoscopic visualization after weaning from by-pass circulation in these types of surgery.

Importance of following protocols in complex cases: order surveillance cultures of all critical care units in which the patient has stayed, in particular in patients transferred to referral units.
FIGURE 2. Contrast CT image illustration the location of the tracheal stenosis and its relationship with the rest of the bronchial tree.

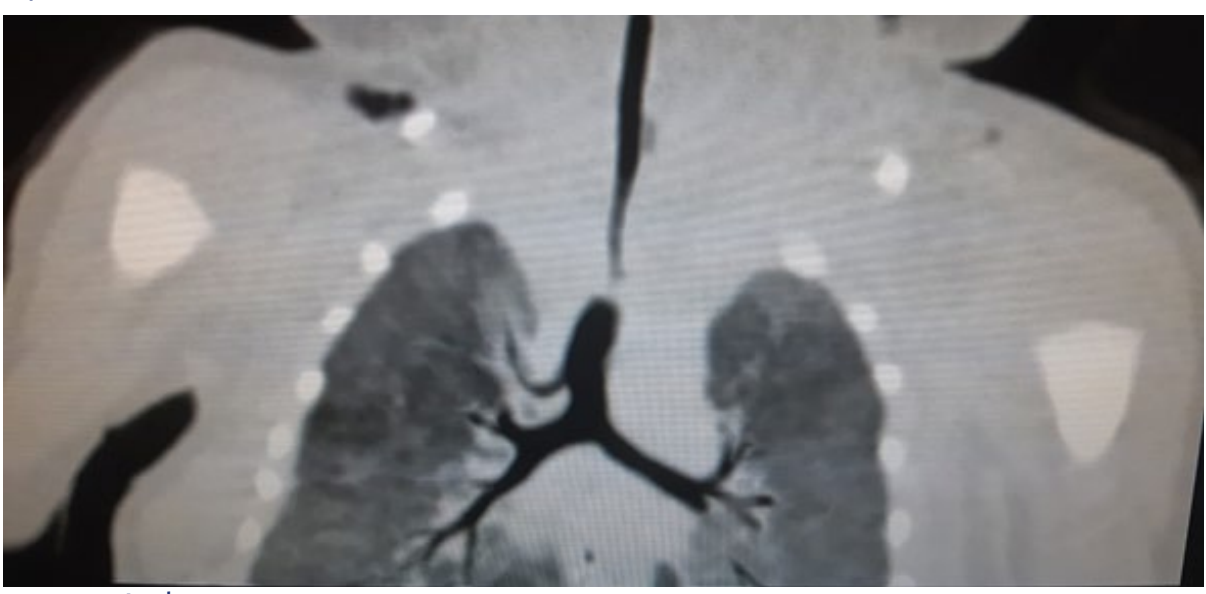

SOURCE: Authors. 


\section{ETHICAL RESPONSIBILITIES}

\section{Human and animal protection}

The authors declare that no human or animal experiments were carried out as part of this research.

\section{Data confidentiality}

The authors declare that all the protocols of their center pertaining to patient information disclosure were followed.

\section{Right to privacy and informed consent}

The authors declare that no patient information appears in this article.

The authors obtained the informed consent of the patients and/or subjects referred to in this article. The forms are kept by the corresponding author.

\section{ACKNOWLEDGEMENTS}

\section{Authors' contributions}

DMC: Study planning. Data collection and references. Initial manuscript drafting. Resident during surgery.
FJEA: Conception of the original project. Study planning. Data collection. Correction of the final manuscript. Assistant during surgery.

PAN: Service leader. Final manuscript approval.

\section{Assistance for the study}

None declared.

\section{Financial support and sponsorship}

None declared.

\section{Conflict of interest}

None declared.

\section{Presentations}

None declared.

\section{Appreciations}

We are grateful to the Anesthesia, Resuscitation and Pain Management of Hospital la Fe in Valencia, Spain.

\section{REFERENCES}

1. Conforti $A$, Valfrè $L$, Scuglia $M$, Trozzi $M$, Meucci D, Sgrò S, Bottero S, Bagolan P. Laryngotracheal abnormalities in esophageal atresia patients: A hidden entity. Front Pediatr. 2018;6:401. doi: https://doi.org/10.3389/ fped.2018.00401

2. Rossi ME, Moreddu E, Macé L, Triglia JM, Nicollas R. Surgical management of children presenting with surgical-needed tracheal stenosis. Int ] Pediatr Otorhinolaryngol. 2018;108:219-223. doi: https://doi. org/10.1016/j.ijporl.2018.02.040

3. Martin B], Holinski P, Noga M, El-Hakim H, Aklabi MA. Neonatal tracheal and intracardiac repair in a high-risk premature infant requiring preoperative ECMO transport. World ] Pediatr Congenit Heart Surg. 2019;10(3):380-3. doi: https://doi.org/10.1177/2150135117696490

4. Usui Y, Ono S, Baba K, Tsuji Y. Pitfalls in the management of congenital tracheal stenosis: is conservative management feasible? Pediatr SurgInt. 2018;34(10):1035-40. doi: https://doi. org/10.1007/s00383-018-4329-y

5. Manning PB, Rutter M], Lisec A, Gupta R, Marino BS. One slide fits all: the versatility of slide tracheoplasty with cardiopulmonary bypass supportfor airway reconstruction in children. ] Thorac Cardiovasc Surg. 2011;141 (1):155-61. doi: https://doi.org/10.1016/j.jtcvs.2010.08.060

6. Obara S, O’Leary JD. Congenital tracheal stenosis: Unanticipated and anticipated difficult airway management in a neonate. A Case Rep. 2014;3(9):120-2. doi: https://doi.org/10.1213/ XAA. 0000000000000070 